\title{
Neutralizing antibodies explain the poor clinical response to Interferon beta in a small proportion of patients with Multiple Sclerosis: a retrospective study
}

\author{
Emilia Sbardella ${ }^{1}$, Valentina Tomassini ${ }^{1,2}$, Claudio Gasperini ${ }^{3}$, \\ Francesca Bellomi ${ }^{4}$, Luca Ausili Cefaro ${ }^{1}$, Vincenzo Brescia Morra ${ }^{5}$, \\ Guido Antonelli ${ }^{4}$ and Carlo Pozzilli*1
}

\begin{abstract}
Address: ${ }^{1}$ Departments of Neurological Sciences, "Sapienza" University, Rome, Italy, ${ }^{2}$ FMRIB Centre, The University of Oxford, Department of Clinical Neurology, John Radcliffe Hospital, Oxford, UK, ${ }^{3}$ Department of Neurology, San Camillo Hospital, Rome, Italy, ${ }^{4}$ Experimental Medicine and Pathology, Section of Virology, "Sapienza" University, Rome, Italy and ${ }^{5}$ Department of Neurological Sciences, "Federico II" University, Naples, Italy

Email: Emilia Sbardella - emilia.sbardella@uniroma1.it; Valentina Tomassini - valentt@fmrib.ox.ac.uk;

Claudio Gasperini - c.gasperini@libero.it; Francesca Bellomi - francesca.bellomi@uniroma1.it; Luca Ausili Cefaro - luca.ausilicefaro@hotmail.it; Vincenzo Brescia Morra - centrosm@unina.it; Guido Antonelli - guido.antonelli@uniroma1.it; Carlo Pozzilli* - carlo.pozzilli@uniroma1.it

* Corresponding author
\end{abstract}

Published: 13 October 2009

BMC Neurology 2009, 9:54 doi:10.1186/147I-2377-9-54

This article is available from: http://www.biomedcentral.com/I47I-2377/9/54

(c) 2009 Sbardella et al; licensee BioMed Central Ltd.

This is an Open Access article distributed under the terms of the Creative Commons Attribution License (http://creativecommons.org/licenses/by/2.0), which permits unrestricted use, distribution, and reproduction in any medium, provided the original work is properly cited.
Received: 26 March 2009

Accepted: 13 October 2009

\begin{abstract}
Background: Neutralizing antibodies (NAbs) against Interferon beta (IFN $\beta$ ) are reported to be associated with poor clinical response to therapy in multiple sclerosis (MS) patients. We aimed to quantify the contribution of NAbs to the sub-optimal response of IFN $\beta$ treatment.

Methods: We studied the prevalence of NAbs in MS patients grouped according to their clinical response to IFN $\beta$ during the treatment period. Patients were classified as: group $A$, developing $\geq$ I relapse after the first 6 months of therapy; group B, exhibiting confirmed disability progression after the first 6 months of therapy, with or without superimposed relapses; group $C$, presenting a stable disease course during therapy. A cytopathic effect assay tested the presence of NAbs in a cohort of ambulatory MS patients treated with one of the available IFN $\beta$ formulations for at least one year. NAbs positivity was defined as NAbs titre $\geq 20$ TRU.

Results: Seventeen patients (I2.1\%) were NAbs positive. NAbs positivity correlated with poorer clinical response $(p<0.04)$. As expected, the prevalence of NAbs was significantly lower in Group C (2.1\%) than in Group A (17.0\%) and Group B (17.0\%). However, in the groups of patients with a poor clinical response (A, B), NAbs positivity was found only in a small proportion of patients.
\end{abstract}

Conclusion: The majority of patients with poor clinical response are NAbs negative suggesting that NAbs explains only partially the sub-optimal response to IFN $\beta$.

\section{Background}

The clinical efficacy of Interferon beta (IFN $\beta$ ) therapy in Multiple Sclerosis (MS) has been demonstrated consist- ently in large, randomized, placebo-controlled trials [1]. However, a proportion of treated patients ranging from $7 \%$ to $49 \%$ show a poor clinical response [2]. 
Mechanisms underlying IFN $\beta$ activity in MS are only partially known. There is evidence suggesting that the interaction between IFN $\beta$ and its receptor is responsible for beneficial effects of IFN $\beta[3,4]$. Exposure to IFN $\beta$, however, can result in the development of antibodies against the IFN $\beta[5,6]$. Neutralizing antibodies (NAbs) interact with the biologically active sites of the IFN $\beta$ molecule, preventing the interaction of IFN $\beta$ with its receptor and downstream effects. Binding antibodies (BAbs) may bind to several different antigenic epitopes of the IFN $\beta$ molecule, some of which are not involved in the activation of IFN $\beta$ receptors [7]. Moderate or high levels of BAbs developed during the first year of IFN $\beta$ treatment may predict of the subsequent development of NAbs [8].

The development of NAbs can reduce or abrogate IFN $\beta$ bioavailability, as revealed by decreased levels of biological markers of IFN $\beta$ bioactivity, such as neopterin, $\beta_{2}$ microglobulin, and myxovirus resistance protein $\mathrm{A}$, and the reduction in IFN $\beta$ bioavailability may depend on NAbs titres [9-13]. In treated MS patients IFN $\beta$ bioactivity decreases as NAbs develop, returning to the normal levels when NAbs levels fall [14]. In NAbs-negative patients an in vivo biological response to IFN $\beta$ is present, which is not detectable in patients with high NAbs titres [15]. Although the relationship between induction of biological markers and IFN $\beta$ clinical activity is not known, this evidence suggests that NAbs detected by validated in vitro assays may have consequences in vivo.

NAbs against IFN $\beta$ have been largely studied as one of the factors responsible for poor clinical response to therapy in MS. Although many studies have shown that NAbs reduce IFN $\beta$ efficacy, as measured by MRI and clinical disease activity $[5,10,16-25]$, the clinical relevance of NAbs, especially at low titres, in MS patients treated with IFN $\beta$ remains debatable $[26,27]$.

It remains, however, to be established whether NAbs play a major role in determining a poor clinical response to IFN $\beta$. Here, we aim to quantify the percentage of NAbs positivity among sub-optimal responder patients to determine to what extent NAbs contribute to IFN $\beta$ response in MS. This could inform clinicians on the contribution of NAbs detection to IFN $\beta$ response and support clinical decision making.

\section{Methods}

Patients

We included patients with a diagnosis of relapsing-remitting MS (RRMS) or secondary-progressive MS (SPMS) [28] receiving IFN $\beta$ treatment as a first line therapy and undergoing routine assessment at the MS University Outpatient Services of Rome, "Sapienza" University, and Naples, "Federico II" between January 2004 and December 2005.
Patients aged from 18 to 55 years were eligible if they had a score of 6.0 or lower on the Expanded Disability Status Scale (EDSS) [29]. Patients with RRMS should have experience at least two relapses supported by history and confirmed by physical examination, during the 2 years prior to the commencement of therapy. Patients with SPMS were eligible if they had experienced a sustained disability progression for at least 6 months after an initial RRMS course of disease. Only patients taking IFN $\beta$ therapy for at least 12 months prior to study entry were included. RRMS patients were undergoing treatment with standard doses of one of the IFN $\beta$ formulations available; treatment for SPMS was restricted to IFN $\beta-1 \mathrm{~b}$, the only drug licensed in Italy for treatment of SPMS. The Ethics Committees of the two University Hospitals approved the study.

\section{Demographic and clinical assessments}

Demographic and clinical data were regularly recorded at each 6-month visit on the on-site database.

A relapse was defined as the appearance or re-appearance of one or more symptoms attributable to MS, accompanied by objective deterioration lasting at least 24 hours on neurological examination, in the absence of fever, and preceded by neurological stability for at least 30 days [30]. The relapse were assessed by a trained neurologist and in the event of a disabling relapse, patients received a standard course of steroids (methylprednisolone, $1 \mathrm{~g} /$ day intravenously) for 5 days.

\section{Definitions of response to IFN $\beta$ therapy}

We defined three groups of patients according to the clinical response to IFN $\beta$, based on disability progression and the number of relapses over the study period:

\section{Group A}

patients experiencing relapses without confirmed disease progression during the treatment period before NAbs testing. Relapses occurred in the first 6 months of therapy were not counted.

\section{Group B}

patients who experienced an increase of $\geq 1.0$ point of the EDSS, or $\geq 0.5$ points if baseline EDSS score was $\geq 5$, with confirmed disease progression at 6 months, persisting for at least 2 consecutive scheduled visits, with or without superimposed relapses during the treatment period; the EDSS at the time of the relapse was not considered in the definition of disease progression. Patients without a confirmatory exam were excluded from the study.

\section{Group C}

patients with a clinically stable disease, i.e. without relapses and/or disability progression during the study period. Within each group, patients were stratified accord- 
ing to the type of IFN $\beta$ formulation with which they were treated.

Twelve out of 141 patients (8.5\%) were treated with IFN $\beta$ 1a 30 mcg (Avonex ${ }^{\oplus}$; Biogen Idec, Cambridge, MA), administered intramuscularly once a week (hereafter 'Avonex'); 36 (25.5\%) were treated with IFN $\beta$-1b 8 MIU (Betaferon"; Bayer-Schering Pharma, Berlin, Germany), administered subcutaneously every other day (hereafter 'Betaferon'); 48 (34.0\%) were treated with IFN $\beta-1 \mathrm{a} 22$ mcg (Rebif 22 ${ }^{\circledast}$; Merck Serono International S.A., Geneva, Switzerland, an affiliate of Merck KGaA, Darmstadt, Germany), administered three times a week (hereafter 'Rebif $\left.22^{\prime}\right)$; and $45(31.9 \%)$ patients were treated with IFN $\beta-1 \mathrm{a}$ $44 \mathrm{mcg}$ (Rebif 44; Geneva, Switzerland, an affiliate of Merck KGaA, Darmstadt, Germany), administered three times a week (hereafter 'Rebif 44').

\section{NAbs assessment}

A blood sample was taken once during the study, at least 12 months after starting IFN $\beta$ treatment, to test for the presence of NAbs (Figure 1). Patients did not receive corticosteroids in the month preceding blood sampling and had not been treated with immunosuppressive drugs associated with IFN $\beta$. At the time of blood sampling, EDSS was assessed. Response to therapy, i.e. patients' classification into groups A, B or C, was defined on the basis of the neurological assessment performed at the time of blood sampling for the NAbs test.

Blood samples were allowed to clot at room temperature for an hour prior to centrifugation. Sera were collected and stored at $-20^{\circ} \mathrm{C}$ in small aliquots until analysis. The presence of NAbs to IFN $\beta$ was tested using a cytopathic effect (CPE) assay against 10 IU of recombinant IFN $\beta-1$ a or IFN $\beta-1 \mathrm{~b}$ [31]. Sera were inactivated at $56^{\circ} \mathrm{C}$ for $30 \mathrm{~min}$ utes before titration. Two-fold serial dilutions (starting from $1: 10$ ) of sample or control sera in $60-\mu \mathrm{L}$ volumes were incubated with $60 \mu \mathrm{L}$ of $20 \mathrm{IU} / \mathrm{mL}$ of each type of IFN $\beta$ at $37^{\circ} \mathrm{C}$ for an hour. Next, $100 \mu \mathrm{L}$ of individual sample mixtures were added to duplicate monolayers of human lung carcinoma (A549) cells in 96-well microtitre plates. After 18 to 24 hours of culture and extensive washing, cells were exposed to encephalomyocarditis virus, followed by incubation at $37^{\circ} \mathrm{C}$ for 24 hours. Controls included a titration of the IFN preparation used in the assay.

Antiviral activity and its neutralization were assessed on the basis of virus-induced CPE. To quantify the CPE, cells were stained with crystal violet in $20 \%$ ethanol, followed by elution of dye taken up by the cells with $33 \%$ acetic acid. The extent of virus-induced CPE, its inhibition by recombinant IFN $\beta$, and the reversal of this by NAbs were shown by the amount of dye eluted from each sample. Titres were calculated using Kawade's method [32], and

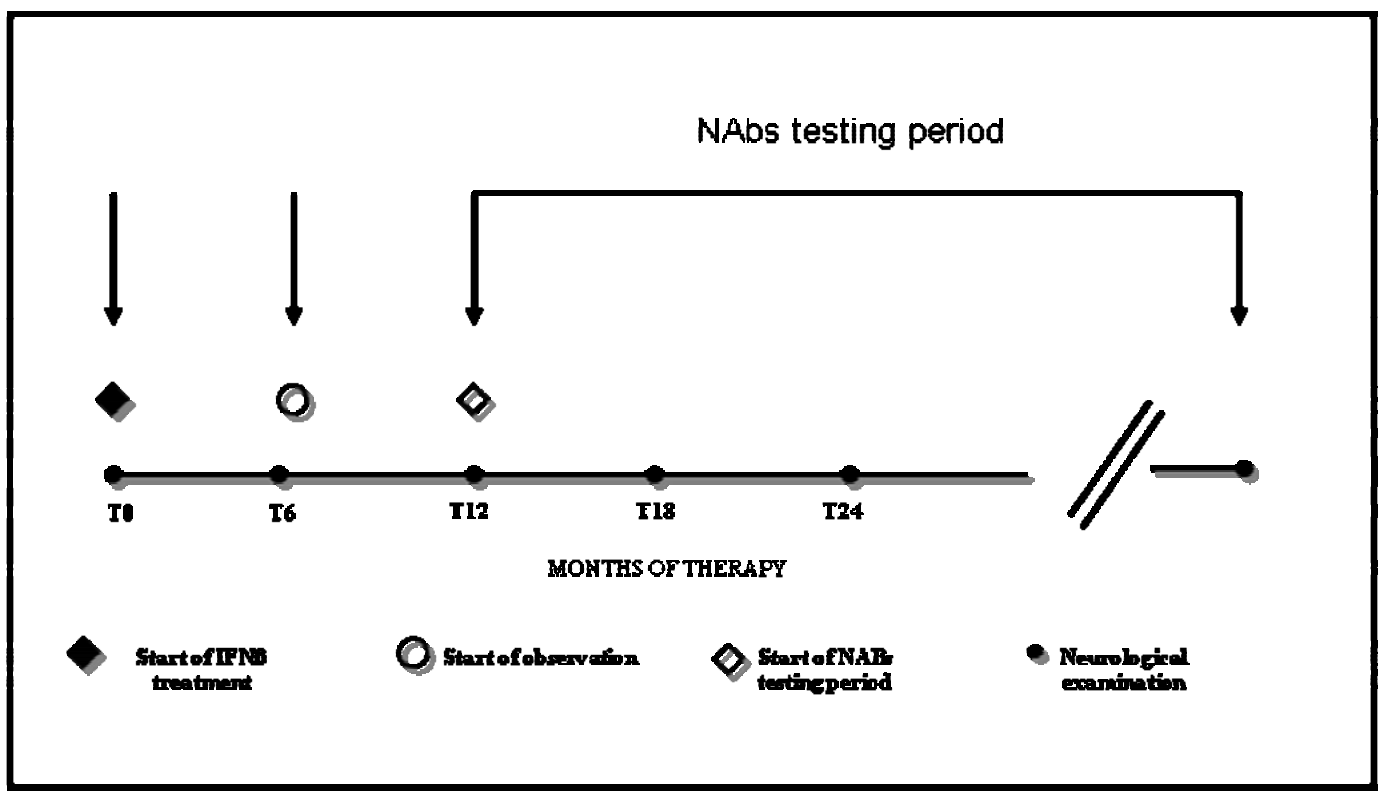

Figure I

Timeline of the study. The blood sample to test for the presence of NAbs was taken once during the study, at least 12 months after starting IFN $\beta$ treatment. Relapses or EDSS progression occurred in the first 6 months of therapy were not counted. 
expressed as ten-fold reduction units (TRU), namely, the dilution of serum that reduces 10 laboratory units (LU) per $\mathrm{mL}$ of IFN to $1 \mathrm{LU} / \mathrm{mL}$ [33]. Serum samples underwent routine assay and were found to be free of endogenous or residual IFN activity. None of the sera showed an intrinsic antiviral activity and therefore no sera were excluded.

Patients were classified according to their NAbs status into NAbs-negative and NAb-positive patients. NAbs-positivity was defined as a titre of $\geq 1: 20$ neutralizing units. Once classified as NAbs-positive or NAbs-negative, patients kept their classification for the duration of the study according to the definition "anytime positive, always positive" [16].

\section{Statistical analysis}

The influence of NAbs on clinical efficacy, including clinically documented relapses and confirmed disability progression, was tested. Differences between groups were analyzed using nonparametric tests (Pearson chi-squared test) for qualitative and categorical variables, and parametric tests (Student's $t$-test for independent samples or univariate analysis of variance) for quantitative variables. The Bonferroni post-hoc test was used for multiple comparisons and the paired $t$-test was used to compare the same variables at different times. Analyses were performed using SPSS version 8.0 software (SPSS Inc., Chicago, USA). Significance was set at $p<0.05$.

\section{Results}

\section{Baseline demographic and clinical characteristics}

Data were collected retrospectively from 141 patients (90 women and 51 men) with a mean ( \pm standard deviation, SD) age of $38.6( \pm 9.7)$ years, disease duration since the first clinical event suggestive of MS, of $10.98( \pm 6)$ years and a median EDSS score of 2 (range: 0-6.0). The mean ( \pm standard deviation, SD) of treatment duration before Nabs testing was $4.3( \pm 2.1)$ years (range $1-10)$.
Patients treated with Betaferon were older and had higher baseline EDSS scores than patients treated with Rebif 22 or Rebif 44 (Table 1). Durations of disease and treatment were also longer in the Betaferon- than in Rebif-treated patients.

When the entire cohort of patients was grouped according to the clinical response, within each group ( $\mathrm{n}=47), 4$ patients were treated with Avonex, 12 with Betaferon, 16 with Rebif 22, and 15 with Rebif 44. The three response groups were similar in terms of baseline demographic and clinical characteristics (Table 2).

\section{NAbs status and clinical response to IFN $\beta$ therapy}

The presence of NAbs was tested in all patients after starting IFN $\beta$ treatment (median 4 years, range 1-10 years). Fifty-nine (42\%) patients were tested between the first and the third year after the beginning of IFN $\beta$, while 82 $(58 \%)$ were tested after the third year of treatment.

\section{Whole cohort}

NAbs were detected in 17 patients (12.1\%). Eight out of 17 NABs-positive patients were tested after the third year of therapy. Seventy-four out of 124 NAbs-negative $(59.7 \%)$ patients were tested after the third year of therapy.

Baseline demographic and clinical characteristics did not differ between NAbs-positive and NAbs-negative patients (Table 3), with the exception of age, as NAbs-negative patients were younger $(p<0.05)$.

\section{Treatment group}

When NAb-positivity was assessed on the basis of the treatment group, one patient (8.3\%) treated with Avonex, $5(13.9 \%)$ treated with Betaferon, $6(12.5 \%)$ treated with Rebif 22, and $5(11.1 \%)$ treated with Rebif 44 were found to be NAbs-positive (Table 3 ). No significant differences

Table I: Baseline characteristics of the patients grouped according to the IFN $\beta$ formulation

\begin{tabular}{|c|c|c|c|c|c|}
\hline Characteristics & $\begin{array}{c}\text { Avonex } \\
n=12\end{array}$ & $\begin{array}{c}\text { Rebif } 22 \\
n=48\end{array}$ & $\begin{array}{c}\text { Rebif } 44 \\
n=45\end{array}$ & $\begin{array}{c}\text { Betaferon } \\
n=36\end{array}$ & $p$ \\
\hline Age (years) & $\begin{array}{c}39.9 \pm 10.8 \\
(27-64)\end{array}$ & $\begin{array}{c}38.7 \pm 9.1 \\
(23-58)\end{array}$ & $\begin{array}{c}35 \pm 8.4 \\
(21-58)\end{array}$ & $\begin{array}{c}42.6 \pm 10.1 \\
(25-67)\end{array}$ & 0.04 \\
\hline Disease duration (years) & $\begin{array}{c}12.3 \pm 6.6 \\
(5-24)\end{array}$ & $\begin{array}{c}9.9 \pm 5.3 \\
(2-24)\end{array}$ & $\begin{array}{c}9.7 \pm 5.4 \\
(3-28)\end{array}$ & $\begin{array}{c}13.6 \pm 6.8 \\
(3-34)\end{array}$ & 0.01 \\
\hline Therapy duration (years) & $\begin{array}{c}4.7 \pm 1.7 \\
(2-8)\end{array}$ & $\begin{array}{c}4.2 \pm 1.6 \\
(1-9)\end{array}$ & $\begin{array}{c}3.2 \pm 1.8 \\
(1-10)\end{array}$ & $\begin{array}{c}5.7 \pm 2.5 \\
(1-10)\end{array}$ & 0.001 \\
\hline EDSS score & $\begin{array}{c}1.8 \pm 1.0 \\
(1-4.5)\end{array}$ & $\begin{array}{c}1.9 \pm 1.0 \\
(0-5)\end{array}$ & $\begin{array}{c}2.0 \pm 1.2 \\
(0-5.5)\end{array}$ & $\begin{array}{c}2.65 \pm 1.5 \\
(0-6)\end{array}$ & 0.02 \\
\hline
\end{tabular}

All values are mean $\pm S D$ (range) 
Table 2: Baseline characteristics of the patients grouped according to the clinical response to IFN $\beta$

\begin{tabular}{|c|c|c|c|c|}
\hline Characteristics & $\begin{array}{c}\text { Group A } \\
(n=47)\end{array}$ & $\begin{array}{c}\text { Group B } \\
(n=47)\end{array}$ & $\begin{array}{l}\text { Group C } \\
(n=47)\end{array}$ & $p$ \\
\hline Age (years) & $\begin{array}{c}38.2 \pm 10 \\
(23-64)\end{array}$ & $\begin{array}{c}40.4 \pm 10.8 \\
(21-67)\end{array}$ & $\begin{array}{c}37.3 \pm 7.9 \\
(23-56)\end{array}$ & 0.29 \\
\hline Disease duration (years) & $\begin{array}{c}10.6 \pm 5.3 \\
(3-24)\end{array}$ & $\begin{array}{c}12.5 \pm 6.3 \\
\quad(4-34)\end{array}$ & $\begin{array}{c}9.9 \pm 6.3 \\
(2-28)\end{array}$ & 0.11 \\
\hline Therapy duration (years) & $\begin{array}{c}4.4 \pm 2.3 \\
(I-10)\end{array}$ & $\begin{array}{c}4.1 \pm 1.9 \\
(1-10)\end{array}$ & $\begin{array}{c}4.3 \pm 2.2 \\
(1-10)\end{array}$ & 0.79 \\
\hline
\end{tabular}

All values are means $\pm S D$ (range)

Group A: patients experiencing at least one relapse after the first 6 months of therapy without confirmed disease progression. Group B: patients experiencing a sustained disability progression (increase of $\geq 1.0$ point on the EDSS, or $\geq 0.5$ points if baseline EDSS score was $\geq 5.5$ ) with or without superimposed relapses during the treatment period. Group C: patients with a stable disease, i.e., no relapse and/or disability progression.

were observed between NAbs-positive and NAbs-negative patients according to IFN $\beta$ preparation.

\section{Response group}

When the presence of NAbs was considered according to the clinical response to therapy, a significant interaction was found between clinical response and NAbs development $(p<0.04)$. The prevalence of NAbs was higher in groups showing poor clinical response (Group A: 17.0\%; Group B: $17.0 \%)$ than in patients with clinically stable disease (Group C: 2.1\%). However, within groups with a suboptimal response (Group A and Group B) only 16 out of $94(17 \%)$ patients were NAbs-positive, whereas 78 were NAbs-negative (Figure 2). Forty-nine out of 78 (63\%) NAbs-negative patients underwent the blood sampling after the third year of therapy.

\section{Discussion}

This study shows that the prevalence of NAbs is higher in patients who experience relapses or disability progression during IFN $\beta$ therapy than in patients with stable disease. However, NAbs seem to explain only partially the poor clinical response to IFN $\beta$ treatment, as only a small proportion of patients with poor response to IFN $\beta$ become Nabs-positive while on disease modifying treatment.

The development of NAbs has been reported to reduce treatment efficacy $[5,16,34]$ and their clinical relevance is correlated with titre and persistence of antibodies. Hightitre, persistent NAbs have been consistently shown to impair the activity of IFN $\beta$, whereas low-titre NAbs appear to have a milder effect [26,35-37]. In the present study, NAbs status accounted for a small percentage of nonresponders: only $17.0 \%(16 / 94)$ of patients with either

Table 3: Baseline characteristics of the patients grouped according to the presence of Nabs

\begin{tabular}{|c|c|c|c|}
\hline \multirow[t]{2}{*}{ Characteristics } & \multicolumn{2}{|c|}{ NAbs status } & \multirow[t]{2}{*}{$\boldsymbol{P}$} \\
\hline & $\begin{array}{l}\text { Negative } \\
(n=124)\end{array}$ & $\begin{array}{l}\text { Positive } \\
(n=17)\end{array}$ & \\
\hline \multicolumn{4}{|l|}{ Gender } \\
\hline Female & 80 [64.5] & $10[58.8]$ & 0.65 \\
\hline Male & $44[35.5]$ & $7[41.2]$ & 0.65 \\
\hline Age (years) & $38 \pm 9.4(2 \mid-64)$ & $43 \pm 10.8(31-67)$ & 0.046 \\
\hline Disease duration (years) & $\mathrm{II} \pm 5.8(2-29)$ & $\mathrm{II} \pm 7.4(3-34)$ & 0.92 \\
\hline Treatment duration (in years) & $4 \pm 2.2(1-10)$ & $4 \pm 1.7(1-7)$ & 0.14 \\
\hline IFN $\beta$ type & & & 0.96 \\
\hline Avonex $(n=12)$ & II [8.9] & $\mathrm{I}[5.9]$ & \\
\hline Betaferon $(n=36)$ & $31[25.0]$ & $5[29.4]$ & \\
\hline Rebif $22(n=48)$ & $42[33.8]$ & $6[35.3]$ & \\
\hline Rebif $44(n=45)$ & $40[32.3]$ & 5 [29.4] & \\
\hline
\end{tabular}

Data are percentage [\%] or mean \pm SD (range) 


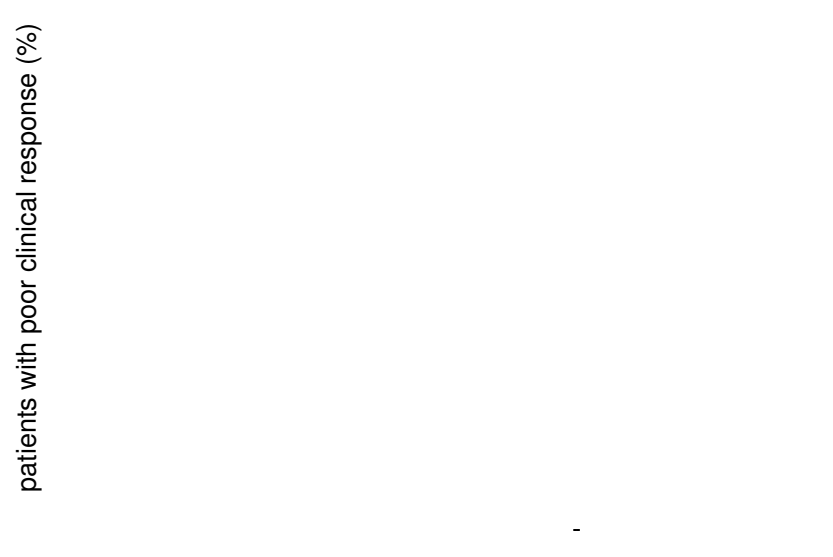

\section{Figure 2}

Prevalence of NAbs according to the clinical

response. Within the groups of patients showing poor clinical response (Group A and B), only 16 out of 94 patients ( $17.0 \%)$ are NAb-positive and 78 (83\%) are NAb-negative. This suggests that NAbs presence explains only partially the poor clinical response to IFN $\beta$.

relapses or disease progression over the treatment period were NAbs-positive at the time of blood sample. Although the impact of IFN $\beta$ is different in RRMS and SPMS [1] and IFN $\beta$ mainly acts as anti-inflammatory drug, in our study the prevalence of NAbs was similar in Group A and B. This may suggests that the development of NAbs abrogating IFN $\beta$ bioavailability have the same negative influence on disease worsening both in terms of relapses and EDSS progression.

The low prevalence of NAbs in patients with poor response to therapy brings into question the clinical impact of these antibodies on treatment efficacy. Absence of NAbs does not guarantee IFN $\beta$ efficacy, as a large proportion of patients who experience relapses or disability progression do not develop NAbs. Indeed, risk factors for a poor response to therapy that are independent from NAbs status have been described. Genetic polymorphisms may constitute intrinsic determinants of individual differences in response to IFN $\beta[38,39]$.

The contribution of NAbs to clinical response to IFN $\beta$ depends on the definition of responders. Previously, different definitions of non-responders to IFN $\beta$ therapy have been proposed but none of them have been validated in long-term follow-up studies $[2,40]$. A reduction in the number of relapses was used to define responders to therapy. However, this definition is weakened by the phenomenon of 'regression to the mean' [2]. In this study, responders were defined as patients who had never experienced a relapse during treatment. We used disability progression confirmed at 6 months to identify patients with a poor response; this definition has been shown to have good sensitivity and specificity [2].
NAbs development was not predictable on the basis of baseline characteristics. We did not find significant relationships between NAbs status and baseline characteristics. However, younger patients were marginally more likely to remain NAbs-negative than older patients [18].

The overall prevalence of NAbs observed in this study (12.1\%) was lower than reported previously [5,15-17], but was similar to that shown in patients treated with IFN $\beta$ for 3 to 10 years [41]. Several factors may explain these differences in prevalence.

NAbs appearance may have been influenced by the definition of NAbs positivity. Here we used an "any-time positive, always positive" definition, testing patients only once to determine the presence of NAbs. As we used the singlesample method and obtained samples at variable time intervals from the beginning of therapy ranging from 1 to 10 years, fluctuations in NAbs titres (and NAbs status) cannot be completely ruled out. Previous studies have shown that NAbs can be transitory and that some NAbspositive patients, particularly those with low titers, may sero-revert to a negative status over time despite ongoing IFN $\beta$ treatment $[7,16,31]$. The low prevalence of NAbs $(12.1 \%)$ in this study, especially in patients treated with INF $\beta-1 \mathrm{~b}$, may be related to the longer duration of treatment. Indeed, 58 patients were tested for NAbs after the third year of treatment, allowing for sufficient time for NAbs to disappear. Therefore, many of the NAbs-negative patients could have been positive during the first years of treatment. It has been shown that, returning to a NAbsnegative state, treated patients may regain a biologic response to IFN $\beta$ [42], but whether this will result in a restoration of the therapeutic efficacy remains unclear. A recent study suggests that after reverting from a NAbs-positive to a NAbs-negative status, the therapeutic effect of IFN- $\beta-1 b$ on relapses is restored [43].

\section{Conclusion}

Although evidence suggests that the development of NAbs can adversely affect IFN $\beta$ efficacy, we suggest that NAbspositivity explains the poor response to IFN $\beta$ treatment only in a small proportion of patients with MS and their appearance should be weighted against other factors hampering the response to treatment.

\section{Competing interests}

$\mathrm{CP}$ received honoraria for consultancy or speaking from Biogen, Bayer Schering, Merck Serono and research grants from Merck Serono; GA received research grants from Merck Serono, Biogen and Bayer Schering; VBM received research grants from Merck Serono, and Bayer Schering; CG received honoraria for consultancy or speaking from Biogen, Bayer Schering, Meck Serono and research grants from Bayer Schering. 


\section{Authors' contributions}

ES, LAC, CP: have made substantial contributions to conception and design, acquisition of data, analysis and interpretation of data. FB: carried out the immunoassays. VT, CG, GA: have been involved in revising the manuscript critically for important intellectual content. All authors have given final approval of the version to be published.

\section{Acknowledgements}

The Authors would like to thank the MS Society Italy (Fondazione Italiana Sclerosi Multipla, FISM) (VT, CP) and MS Society UK (VT) for their support, Andrea Plant, PhD, (Merck Serono International S.A., Geneva, Switzerland) for assistance with the preparation of the manuscript, Orietta Picconi (Laziosanità, Agenzia di Sanità Pubblica, Rome, Italy) for support with the statistical analyses, and Gianluigi Lenzi, MD, for useful discussions about the interpretation of the results.

The principal investigator had full access to all of the data in the study and takes responsibility for the integrity of the data and the accuracy of the data analysis.

\section{References}

I. Goodin DS, Frohman EM, Garmany GP Jr, Halper J, Likosky WH, Lublin FD, Silberberg DH, Stuart WH, Noort S Van den: Disease modifying therapies in multiple sclerosis: report of the Therapeutics and Technology Assessment Subcommittee of the American Academy of Neurology and the MS Council for Clinical Practice Guidelines. Neurology 2002, 58:169-178.

2. Río J, Nos C, Tintoré M, Galán I, Pelayo R, Comabella M, Montalban $X$ : Defining the response to interferon-beta in relapsingremitting multiple sclerosis patients. Ann Neurol 2006, 59:344-52.

3. Yong WW, Chabot S, Stuve O, Williams G: Interferon beta in the treatment of multiple sclerosis: mechanisms of action. Neurology 1998, 5 I:682-689.

4. Chofflon M: Mechanisms of action for treatments in multiple sclerosis: Does a heterogeneous disease demand a multi-targeted therapeutic approach? BioDrugs 2005, 19:299-308.

5. The IFNB Multiple Sclerosis Study Group and the University of British Columbia MS/MRI Analysis Group: Neutralizing antibodies during treatment of multiple sclerosis with interferon beta-I b: experience during the first three years. Neurology 1996, 47:889-894

6. Antonelli G, Bagnato F, Dianzani F: Considerations on the development of serum antibodies to interferon-beta. New Microbiol 2005, 28: $183-192$

7. Gneiss C, Reind M, Berger T, Lutterotti A, Ehling R, Egg R, Deisenhammer F: Epitope specificity of neutralizing antibodies against IFN-beta. J Interferon Cytokine Res 2004, 24:283-90.

8. Pachner AR, Brady J, Steiner I, Narayan K: Management of neutralizing antibodies against beta-IFN in beta-IFN-treated multiple sclerosis patients. J Neurol 2008, 255:18I5-7.

9. Bertolotto A, Gilli F, Sala A, Capobianco M, Malucchi S, Milano E, Melis F, Marnetto F, Lindberg RL, Bottero R, Di Sapio A, Giordana MT: Persistent neutralizing antibodies abolish the interferon beta bioavailability in MS patients. Neurology 2003, 60:634-639.

10. Rudick RA, Simonian NA, Alam JA, Campion M, Scaramucci JO, Jones W, Coats ME, Goodkin DE, Weinstock-Guttman B, Herndon RM, Mass MK, Richert JR, Salazar AM, Munschauer FE 3rd, Cookfair DL, Simon JH, Jacobs LD: Incidence and significance of neutralizing antibodies to interferon beta- Ia in multiple sclerosis. Multiple Sclerosis Collaborative Research Group (MSCRG). Neurology 1998, 50:1266-1272.

II. Pachner AR, Bertolotto A, Deisenhammer F: Measurement of MxA mRNA or protein as a biomarker of IFNbeta bioactivity: detection of antibody-mediated decreased bioactivity (ADB). Neurology 2003, 61:S24-S26.

12. Deisenhammer F, ReindI M, Harvey J, Gasse T, Dilitz E, Berger T: Bioavailability of interferon beta $I b$ in MS patients with and without neutralizing antibodies. Neurology 1999, 52:|239-I 243.
13. Scagnolari C, Duda P, Bagnato F, De Vito G, Alberelli A, Lavolpe V, Girardi E, Durastanti V, Trojano M, Kappos L, Antonelli G: Pharmacodynamics of interferon beta in multiple sclerosis patients with or without serum neutralizing antibodies. J Neurol 2007, 254:597-604.

14. Pachner AR, Dail D, Pak E, Narayan K: The importance of measuring IFNbeta bioactivity: monitoring in MS patients and the effect of anti-IFNbeta antibodies. I Neuroimmunol 2005, 166: $180-188$.

15. Sorensen PS, Tscherning T, Mathiesen HK, Langkilde AR, Ross C, Ravnborg M, Bendtzen K: Neutralizing antibodies hamper IFNbeta bioactivity and treatment effect on MRI in patients with MS. Neurology 2006, 67:168I-1683.

16. Francis GS, Rice GP, Alsop JC: Interferon beta-Ia in MS: results following development of neutralizing antibodies in PRISMS. Neurology 2005, 65:48-55.

17. Sorensen PS, Ross C, Clemmesen KM, Bendtzen K, Frederiksen JL, Jensen K, Kristensen O, Petersen T, Rasmussen S, Ravnborg M, Stenager E, Koch-Henriksen N, Danish Multiple Sclerosis Study Group: Clinical importance of neutralising antibodies against interferon beta in patients with relapsing-remitting multiple sclerosis. Lancet 2003, 362: I 184- II91.

18. Polman C, Kappos L, White R, Dahlke F, Beckmann K, Pozzilli C, Thompson A, Petkau J, Miller D, European Study Group in Interferon Beta-Ib in Secondary Progressive MS: Neutralizing antibodies during treatment of secondary progressive MS with interferon beta-Ib. Neurology 2003, 60:37-43.

19. Kappos L, Clanet M, Sandberg-Wollheim M, Radue EW, Hartung HP, Hohlfeld R, Xu J, Bennett D, Sandrock A, Goelz S: European Interferon Beta-Ia IM Dose-Comparison Study Investigators. Neutralizing antibodies and efficacy of interferon beta-Ia: a 4-year controlled study. Neurology 2005, 65:40-47.

20. Perini $P$, Calabrese M, Biasi G, Gallo P: The clinical impact of interferon beta antibodies in relapsing-remitting $\mathbf{M S}$. J Neurol 2004, 25 I:305-309.

21. Li DK, Zhao GJ, Paty DW, The UBC MS/MRI Study Group, The SPECTRIMS Study Group: Randomized controlled trial of interferon-beta- I a in secondary progressive MS: MRI results. Neurology 2001, 56:1505-1513.

22. Durelli L, Verdun E, Barbero P, Bergui M, Versino E, Ghezzi A, Montanari E, Zaffaroni M, Independent Comparison of Interferon (INCOMIN) Trial Study Group: Every-other-day interferon beta-I b versus once-weekly interferon beta-I a for multiple sclerosis: results of a 2-year prospective randomised multicentre study (INCOMIN). Lancet 2002, 359:|453-|460.

23. Panitch H, Goodin DS, Francis G, Chang P, Coyle PK, O'Connor P, Monaghan E, Li D, Weinshenker B, EVIDENCE Study Group, EVidence of Interferon Dose-response: Randomized, comparative study of interferon beta-I a treatment regimens in MS: the EVIDENCE trial. Neurology 2002, 59:1496-1506.

24. Malucchi S, Sala A, Gilli F, Bottero R, Di Sapio A, Capobianco M, Bertolotto $A$ : Neutralizing antibodies reduce the efficacy of betalFN during treatment of multiple sclerosis. Neurology 2004, 62:203I-2037.

25. Tomassini V, Paolillo A, Russo P, Giugni E, Prosperini L, Gasperini C, Antonelli G, Bastianello S, Pozzilli C: Predictors of long-term clinical response to interferon beta therapy in relapsing multiple sclerosis. J Neurol 2006, 253:287-293.

26. Hesse D, Sorensen PS: Using measurements of neutralizing antibodies: the challenge of IFN-beta therapy. Eur J Neurol 2007, 14:850-859.

27. Rot U, Sominanda A, Fogdell-Hahn A, Hillert J: Impression of clinical worsening fails to predict interferon-beta neutralizing antibody status. J Int Med Res 2008, 36:1418-25.

28. Lublin FD, Whitaker JN, Eidelman BH, Miller AE, Arnason BG, Burks JS: Management of patients receiving interferon beta-I $b$ for Multiple Sclerosis: report of a consensus conference. Neurology 1996, 46:12-18.

29. Kurtzke JF: Rating neurological impairment in Multiple Sclerosis. An expanded disability status scale (EDSS). Neurology 1983, 33:|444-|452.

30. McDonald WI, Compston A, Edan G, Goodin D, Hartung HP, Lublin FD, McFarland HF, Paty DW, Polman CH, Reingold SC, SandbergWollheim M, Sibley W, Thompson A, Noort S van den, Weinshenker BY, Wolinsky JS: Recommended diagnostic criteria for multi- 
ple sclerosis: guidelines from the International Panel on the diagnosis of multiple sclerosis. Ann Neurol 200I, 50:12I-127.

31. Bellomi F, Scagnolari C, Tomassini V, Gasperini C, Paolillo A, Pozzilli C, Antonelli G: Fate of neutralizing and binding antibodies to IFN beta in MS patients treated with IFN beta for 6 years. J Neurol Sci 2003, 2 i 5:3-8.

32. Kawade Y: Quantitation of neutralization of interferon by antibody. Methods Enzymol 1986, I 1 9:558-573.

33. Grossberg SE, Kawade Y, Kohase M, Klein JP: The neutralization of interferons by antibody. II. Neutralizing antibody unitage and its relationship to bioassay sensitivity: the tenfold reduction unit. J Interferon Cytokine Res 200I, 2 I:743-755.

34. Sorensen PS, Koch-Henriksen N, Bendtzen K: Are ex vivo neutralising antibodies against IFN-beta always detrimental to therapeutic efficacy in multiple sclerosis? Mult Scler 2007 13:616-62|.

35. Goodin DS, Frohman EM, Hurwitz B, O'Connor PW, Oger J], Reder AT, Stevens JC: Neutralizing antibodies to interferon beta: assessment of their clinical and radiographic impact: an evidence report: report of the Therapeutics and Technology Assessment Subcommittee of the American Academy of Neurology. Neurology 2007, 68:977-984.

36. Sorensen PS, Koch-Henriksen N, Ross C, Clemmesen KM, Bendtzen $\mathrm{K}$ : Appearance and disappearance of neutralizing antibodies during interferon-beta therapy. Neurology 2005, 65:33-39.

37. Gneiss C, Reindl M, Lutterotti A, Ehling R, Egg R, Khalil M, Berger T, Deisenhammer F: Interferon-beta: the neutralizing antibody (NAb) titre predicts reversion to NAb negativity. Mult Scler 2004, I 0:507-510.

38. van Baarsen LGM, Vosslamber S, Tijssen M, Baggen JM, van der Voort LF, Killestein J, van der Pouw Kraan TC, Polman CH, Verweij CL: Pharmacogenomics of interferon-beta therapy in multiple sclerosis: baseline IFN signature determines pharmacological differences between patients. PLoS ONE 2008, 3(4): el 927.

39. Gilli F, Valentino P, Caldano M, Granieri L, Capobianco M, Malucchi $S$, Sala A, Marnetto F, Bertolotto A: . Expression and regulation of IFNalpha/beta receptor in IFNbeta-treated patients with multiple sclerosis. Neurology 2008, 71 :1940-7.

40. Waubant E, Goodkin DE, Sloan R, Andersson PB: A pilot study of MRI activity before and during interferon beta-la therapy. Neurology 1999, 53:874-876.

4I. Boz C, Oger J, Gibbs E, Grossberg SE: Reduced effectiveness of long-term interferon-beta treatment on relapses in neutralizing antibody-positive multiple sclerosis patients: a Canadian multiple sclerosis clinic-based study. Mult Scler 2007, 13:1 | 27-1137.

42. Malucchi S, Capobianco M, Gilli F, Marnetto F, Caldano M, Sala A, Bertolotto A: Fate of multiple sclerosis patients positive for neutralising antibodies towards interferon beta shifted to alternative treatments. Neurol Sci 2005, 26:S2 I 3-4.

43. Sorensen PS, Koch-Henriksen N, Flachs EM, Bendtzen K: Is the treatment effect of IFN-beta restored after the disappearance of neutralizing antibodies? Mult Scler 2008, 14:837-42.

\section{Pre-publication history}

The pre-publication history for this paper can be accessed here:

http://www.biomedcentral.com/1471-2377/9/54/prepub

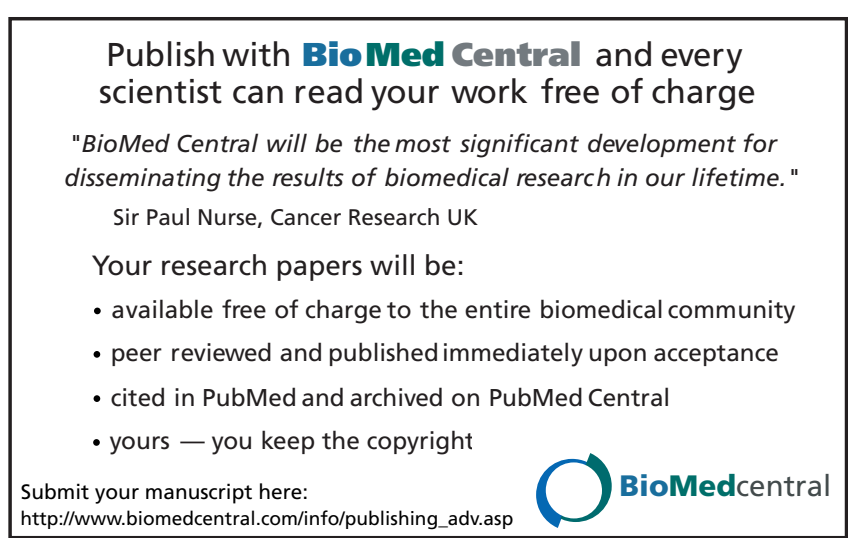

